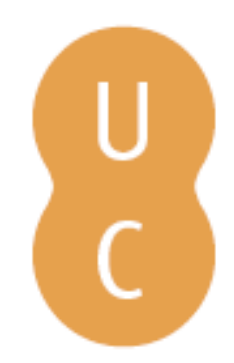

\title{
pompalina
}

\section{O alimento e a sobrevivência em viagens de exploração territorial africana}
Autor(es):
Martins, Luísa Fernanda Guerreiro
Publicado por: Imprensa da Universidade de Coimbra; Annablume
URL
persistente:
URI:http://hdl.handle.net/10316.2/39662
DOI:
DOl:https://doi.org/10.14195/978-989-26-1191-4_32

Accessed : $\quad$ 26-Apr-2023 11:46:55

A navegação consulta e descarregamento dos títulos inseridos nas Bibliotecas Digitais UC Digitalis, UC Pombalina e UC Impactum, pressupõem a aceitação plena e sem reservas dos Termos e Condições de Uso destas Bibliotecas Digitais, disponíveis em https://digitalis.uc.pt/pt-pt/termos.

Conforme exposto nos referidos Termos e Condições de Uso, o descarregamento de títulos de acesso restrito requer uma licença válida de autorização devendo o utilizador aceder ao(s) documento(s) a partir de um endereço de IP da instituição detentora da supramencionada licença.

Ao utilizador é apenas permitido o descarregamento para uso pessoal, pelo que o emprego do(s) título(s) descarregado(s) para outro fim, designadamente comercial, carece de autorização do respetivo autor ou editor da obra.

Na medida em que todas as obras da UC Digitalis se encontram protegidas pelo Código do Direito de Autor e Direitos Conexos e demais legislação aplicável, toda a cópia, parcial ou total, deste documento, nos casos em que é legalmente admitida, deverá conter ou fazer-se acompanhar por este aviso. 


\title{
O ALIMENTO E A SOBREVIVÊNCIA EM VIAGENS DE EXPLORAÇÃO TERRITORIAL AFRICANA The food and survival in African territorial expeditions
}

\author{
Luísa Fernanda Guerreiro Martins \\ Universidade de Évora, Cidehus-Centro Interdisciplinar \\ de História, Culturas e Sociedade; Colaboração no projecto \\ DIAITA - Património Alimentar da Lusofonia \\ martins032@gmail.com
}

Resumo: Em 1798, Francisco José de Lacerda e Almeida, partiu de Tete para proceder à primeira travessia científica de África. Mais tarde, em 1884, Hermenegildo Capelo e Roberto Ivens realizaram a expedição desde Angola a Moçambique, aproveitando o conhecimento de anteriores viajantes. Alguns dos aspectos organizativos das viagens de Lacerda e Almeida e de Capelo e Ivens prenderam-se com os alimentos a levar, para além de uma parafernália de utensílios de cozinha e de mesa. No entanto, as duas viagens, a de 1797 e a de 1884 terão sido precariamente preparadas no que respeitava à prevenção do bem-estar alimentar dos seus participantes. Valeram-lhes os encontros com as populações de aldeias e o sucesso em algumas caçadas, não obstante os dias em que se sofria de fome e de sede. Esta comunicação apresenta um estudo aos diários de Lacerda e de Capelo e Ivens, numa perspectiva da dualidade entre a fome e o festim, procurando registar informação sobre a alimentação das populações que os viajantes foram contactando ao longo das viagens e a forma como os europeus se adaptaram aos espaços, gentes, usos e costumes, para conseguirem sobreviver e prosseguir com os seus objectivos.

Palavras-chave: Fome; Alimento; Viagem; Exploração; Travessia; Encontros; Visão; Povos; Culturas

Summary: In 1798, Francisco José de Lacerda e Almeida left Tete to make the first scientific crossing of Africa. Later, in 1884, Hermenegildo Capelo and Roberto Ivens made the journey from Angola to Mozambique. Some of the organizational aspects of Lacerda e Almeida and Capelo and Ivens were related to the food to take, in addition to a paraphernalia of kitchenware and tableware. However, both expeditions were prepared poorly, with no prevention of food well-being of its members. Their success in some hunting and sharing food with the population they met saved them, despite the days they suffered from hunger and thirst. This paper presents a study of the daily journeys of Lacerda and Capelo, from the perspective of the duality between hunger and the feast, looking to record information about the people that travellers were contacting during their expeditions and how europeans adapted to the spaces, people and customs, in order to survive and pursue their goals.

KeY-words: Hunger; Food; Expeditions; Exploration; Crossing; Meetings; Vision; People; Cultures 


\section{Apresentação}

Desde os primeiros contactos dos portugueses com as civilizações africanas, as relações entre os povos adquiriu formas diversas. Fontes como relatos, diários e crónicas de viagem, relatórios oficiais, documentos diplomáticos, comerciais, militares e missionários tornaram-se essenciais para a escrita da história da presença portuguesa em África e dos povos africanos e ajudam a compreender os elementos que estruturaram a mentalidade europeia ${ }^{1}$.

\section{Fontes E METODOLOGiA}

Duas fontes serviram de base para a realização deste estudo:

a) O "Diário da Viagem de Tete a Cazembe no ano de 1798 ", da autoria do governador dos rios de Sena, matemático e astrónomo Francisco José de Lacerda e Almeida, publicado juntamente com outros diários no volume intitulado Travessia da Africa pelo Dr. Lacerda e Almeida.

b) A obra De Angola a Contracosta em 1884 escrita por Hermenegildo Capelo e Roberto Ivens, resultante da viagem que realizaram de 6 de Janeiro de 1884 a 20 de Setembro de 1885 . Com relato publicado em $1^{\text {a }}$ edição no ano de 1886 pela Imprensa Nacional.

Estes documentos revelam duas realidades que, juntamente a todas as circunstâncias difíceis que rodearam estas viagens, colocaram os seus actores entre a vida e a morte: a existência de alimentos ou a sua ausência. As expedições decorreram sob a batuta da dualidade entre a sobrevivência e a morte, entre a saciedade e a fome. Para além destes apontamentos procurámos ainda compreender os contextos alimentares que encenaram as duas viagens e qual o "olhar" dos viajantes de cultura europeia face às culturas com as quais contactaram.

\section{Considerações prévias}

O primeiro viajante que nos transporta para este estudo é Francisco José de Lacerda e Almeida ${ }^{3}$ (n.1753- f.1798) que foi incumbido pela rainha D.

\footnotetext{
${ }^{1}$ Fage 1982: 43-59.

2 Para o estudo foi usada a versão do ano de 1936, com introdução crítica por Manuel Múrias e, de ora em diante citado como Múrias 1936.

${ }^{3}$ Era filho de um boticário português, José António de Lacerda e de uma brasileira, Francisca de Almeida. Nasceu em S. Paulo no dia 22 de Agosto de 1753. Matriculou-se na Universidade de Coimbra aos 19 anos e, terminado o curso de Matemática e Filosofia, colocou-se ao serviço do rei como geógrafo, matemático e astrónomo, o que o leva a ser escolhido em 1779 para integrar a comissão encarregada de demarcar os limites fronteiriços entre o Brasil e o Paraguai. Em 1790 regressou a Portugal e foi promovido a tenente de
} 
Maria I de realizar a viagem científica desde Tete a Angola. É junto com a mulher e a filha Isabel que, em 1797, partiu rumo a Moçambique como tenente-general dos Rios de Sena. Chegados a Tete em 23 de Janeiro de 1798, começou de imediato a preparar a viagem para a travessia, tendo a sua mulher falecido a 1 de Abril desse mesmo ano, de malária. Muito rapidamente, nesse mesmo ano, contrai segundas núpcias com D. Leonarda Octaviano dos Reis Moreira, sobrinha e herdeira de D. Francisca Josefa de Moura e Meneses, viúva rica, senhora de extensos prazos da coroa, minas de prata e muitos escravos $^{4}$ que vão constituir o grosso da mão-de-obra da expedição.

Realizada num século de desenvolvimento científico e técnico, a necessidade de se registar e medir a ligação entre as colónias portuguesas de Moçambique e de Angola visava alargar o conhecimento cartográfico do território africano, não só para apoiar a política ultramarina que pretendia estancar o avanço dos holandeses desde o sul do continente em direcção ao norte, como também pressupunha que, estabelecendo uma rota comercial terrestre que normalizasse os percursos que já os mercadores africanos faziam há gerações, obviar-se-ia o longo percurso marítimo que ligava a Europa ao Oriente e vice-versa. Para a concretização deste projecto valeu a Portugal o cartógrafo francês Bourguignon d'Anville que, em 1731-1732 demonstrou que a "distância entre os pontos extremos conhecidos das duas costas" ${ }^{5}$ era muito maior e, decerto, difícil, como se verificou pelo trágico fim do projecto de Lacerda e Almeida. E como se virá a comprovar pela viagem dos dois exploradores Hermenegildo Capelo e Roberto Ivens.

Enquanto astrónomo, geógrafo e matemático setecentista, Lacerda insere-se no contexto dos cientistas de origem brasileira que se formaram na Universidade de Coimbra e se notabilizaram nos trabalhos de exploração e de reconhecimento dos territórios de domínio português. Esse trabalho verificou-se no Brasil e em África, marcando Lacerda e Almeida como "primeiro explorador não africano a atingir esta parte de África e a descrevê-la para a ciência europeia"'.

Tendo partido de Tete a 2 de Julho de 1798, a expedição chegou a terras do Cazembe em inícios de Outubro, já muito fragilizada pela constante fuga de carregadores e por conflitos entre os seus elementos. Igualmente débil era o estado de saúde de Lacerda e Almeida que a 17 de Outubro falecia, ficando a

mar e, quatro anos mais tarde, a capitão-de-fragata, desempenhando também funções de lente de Matemática na Real Academia da Marinha. Em Figueiró dos Vinhos, Lacerda e Almeida casou-se por procuração com D. Cecília Craveiro Levache de Faria, da qual teve duas filhas, Isabel Francisca de Faria e Lacerda e Francisca de Lacerda e Almeida Pais.

${ }^{4}$ Martins $1997: 27$.

${ }^{5}$ Santos $1988: 145$.

${ }^{6}$ Rodrigues $1999: 85$. 
expedição por concluir. Antes de morrer, deixou instruções para que o capelão da comitiva, o Padre Francisco João Pinto, o sucedesse e prosseguisse a viagem até Angola. Porém, a comitiva acabou por regressar a Tete sem cumprir a sua missão. A 10 de Dezembro de 1799, o novo governador de Rios de Sena, Jerónimo Pereira, remetia o testamento de Lacerda e Almeida, escrito a 16 de Junho de $1798^{7}$.

Outros viajantes que trazemos para este estudo são Hermenegildo Capelo e Roberto Ivens que não apresentam perfil semelhante ao do cientista setecentista. Ambos de formação militar, abraçam o projecto numa perspectiva exploratória, de ocupação e de vinculação da presença portuguesa no território. A sua expedição foi organizada pela Sociedade de Geografia de Lisboa, com o apoio do governo e do ministro da Marinha e Ultramar, Manuel Pinheiro Chagas. A viagem De Angola à Contracosta estava incluída no programa da Comissão Nacional Portuguesa de Exploração e Civilização da Âfrica, que visava o desenho e o reconhecimento da carta de África centro-austral e do Mapa Cor-de-Rosa, em resposta ao surto expansionista europeu, e que culminou com a Conferência de Berlim em 1885, apanhando Portugal de surpresa, especialmente por causa das duas alíneas incluídas no texto da referida Conferência: uma que clarificava que a potência europeia que possuísse a costa teria direito ao hinterland e, uma outra, que exigia que toda a instalação deveria ser efectivada, o que se afigurava como uma grande barreira a Portugal porque ainda não realizara “a colonização plena nos domínios a que a zona costeira das suas colónias dizia respeito" ${ }^{8}$ nomeadamente, a posse do Congo. Esta viagem viria finalmente encerrar uma pretensão antiga de definição de uma rota comercial que ligaria a costa índica à costa atlântica, obviando-se a centenária Rota do Cabo, que já Lacerda e Almeida pretendera substituir ${ }^{9}$. A experiência revelou a extrema dificuldade na definição de um percurso terrestre, para já não falar da grande distância que implicava a ligação dos extremos das colónias portuguesas. Além disso, a abertura do Canal de Suez em 1869 já permitia a navegação entre a Ásia e a Europa, colocando para segundo lugar a opção pela antiga Rota marítima.

Apesar de se integrarem em contextos políticos e científicos diferentes, as viagens de Lacerda e de Capelo e Ivens visavam a travessia do território africano e a recolha de informações várias, embora a viagem mais recente estivesse integrada num contexto político internacional mais abrangente. No

\footnotetext{
${ }^{7}$ As duas filhas e D. Leonarda seriam as suas únicas herdeiras.

${ }^{8}$ Teresa Bernardino, «As viagens de Capelo e Yvens. Portugal em África na segunda metade do século XIX». http://comum.rcaap.pt/bitstream/123456789/3428/1/NeD36_TeresaBernardino.pdf. (01.09.2014).

${ }_{9}$ Rodrigues 1999: 82.
} 
século XVIII, com as novas experiências de viagens científicas no Brasil e nos territórios de ocupação portuguesa em África, as observações e a forma de "olhar o outro" caracterizam-se pela diferenciação e pela excentricidade. De facto, Lacerda e Almeida, talvez pela sua experiência de vida e de profissão e porque, em rigor, era um cientista, não teceu considerações de menorização do "outro". Podemos mesmo falar de um "olhar científico". Pelo contrário, a viagem de Capelo e Ivens, realizada em pleno século XIX, apresenta um registo que reflecte a ideia da superioridade civilizacional dos europeus face aos africanos. Discurso que vai integrar os programas de colonização até meados do século XX.

Outras viagens realizadas por exploradores e comerciantes durante $o$ século XVIII terão fornecido informação fundamental para a preparação das travessias de Lacerda e de Capelo. No que respeita a Lacerda, podemos mesmo calcular uma opção pela utilização dos caminhos já percorridos por outros viajantes e comerciantes desde o interior em direção ao litoral, no cumprimento das rotas comerciais seculares ${ }^{10}$. Capelo e Ivens optaram por outras rotas, resultantes de estudos que fizeram de experiências anteriores e demais informações, equipados com instrumentos de orientação e de apoio decerto muito mais sofisticados do que os dos viajantes anteriores ${ }^{11}$.

$\mathrm{Na}$ verdade, já uma viagem de travessia tinha sido feita no incío do século XIX por ordem do governador-geral de Angola, Fernando António Soares de Noronha e do tenente-coronel de milícias Francisco Honorato da Costa, pelos pombeiros Pedro João Baptista e Amaro José, com início na feira do Mucari no Cassange no ano de 1802 e término em Tete no ano de 1811. Embora esta viagem não tenha sido reconhecida oficialmente pelas instâncias políticas portuguesas, o certo é que, apesar de longa e muito complicada, cumpriu o objectivo a que se propunha.

Como é sabido, o texto destas memórias de Capelo e de Ivens foi elaborado a posteriori e alguns excertos resultaram de conferências realizadas após um regresso vitorioso a Portugal. Alguns desses textos, para além de relatarem a experiência, assumem a intenção de aconselhar os que pretendem viajar em África. De entre alguns conselhos, sugerem que se tome o quinino ${ }^{12}$ junto ao

${ }^{10}$ Teresa Bernardino, «As viagens de Capelo e Yvens. Portugal em África na segunda metade do século XIX». http://comum.rcaap.pt/bitstream/123456789/3428/1/NeD36_TeresaBernardino.pdf. (01.09.2014).

${ }^{11}$ Capelo e Ivens (s.d.) : I, 14-15.

12 A descoberta do quinino no ano de 1820 permitiu que os exploradores e cientistas conseguissem entrar no continente sem que sucumbissem à malária; o quinino é um sulfato de quinina, substância extraída da tintura de uma árvore americana, a quina, cujo princípio ativo foi pesquisado por Pierre Pelletier e Joseph Caventon. Não está muito claro quem levou a casca de cinchona para a Europa. 
pequeno-almoço ${ }^{13}$. O certo é que Lacerda e Almeida, na viagem de 1798 , nos dá conta de recorrer à quinina para tentar combater as febres de que estava a padecer já no início da viagem. É possível que, sendo originário da América do Sul e com a vasta experiência adquirida nas viagens de delimitação territorial do Brasil, Lacerda e Almeida conhecesse a planta e as propriedades da quina. E segundo nos faz parecer o texto de Lacerda, a quina que tinha não seria a suficiente para o ajudar a combater as febres que o atacavam: "A quina já tinha sustado (sic) o crescimento da moléstia; esta era a única melhora com que me achava, e não era pouca cousa" ${ }^{14}$. E foi esta situação dramática que o levou à morte, depois de ter percorrido 1600 quilómetros desde Tete até ao reino Lunda, onde esteve junto do rei Muata Lequeza, $4^{\circ}$ soberano do Cazembe, tendo aí ficado sepultado em lugar de soberanos, após cerimónias que o próprio rei organizou. E faltavam apenas 800 quilómetros para atingir o Alto Cassai, no território angolano.

\section{A alimentação e a sua Ausência}

Nos textos de Lacerda tudo acaba por se sintetizar em doença, fome, sede e ambiente hostil. O investigador ressente-se de toda esta situação. O seu olhar sobre tudo o que o rodeia vai-se tornando cada vez mais frágil e desolador, talvez já pela tomada de consciência da sua própria incapacidade de sucesso.

Logo que chega a Sena, Lacerda e Almeida tomou conhecimento de que tinha havido um período de fome de 1792 a 1796 mas não teria imaginado as dificuldades que haveria de enfrentar. Durante a viagem, a fome desanimou expedicionários e carregadores: "a falta de mantimentos, e o muito pouco que apareceu, vai pondo em consternação todos os cafres que me acompanhão"15. E a certa altura, Lacerda abdica dos seus tratamentos e bem-estar para garantir que as pessoas que o acompanhavam tivessem comida ${ }^{16}$.

De facto, a preparação da expedição de Lacerda e Almeida foi muito atribulada. A principal dificuldade com que o cientista se defrontou foi a angariação de homens e mulheres, escravos carregadores, para o acompanharem na viagem. Os colonos da região ${ }^{17}$ não queriam ceder a sua mão-de-obra

13 O facto de não existir ainda o quinino como prevenção contra a malária foi fatal no sucesso de projectos similares. A doença foi o principal obstáculo a todos os europeus que tentaram viagens em África, nomeadamente a travessia de Moçambique a Angola, por Francisco José de Lacerda e Almeida, que iniciou a sua viagem em Tete no ano de 1798 e faleceu nesse mesmo ano nas terras de Muata Cazembe, na região do lago Mweru, vítima da malária.

${ }^{14}$ Múrias $1936: 194$.

${ }_{15}$ Múrias $1936: 215$.

${ }^{16}$ Múrias $1936: 216$.

${ }^{17}$ Lacerda manifestou desagrado relativamente aos colonos, proprietários de terras e de escravos, que tratavam homens e mulheres com barbaridade. 
para uma causa que consideravam de impossível concretização. Também não viam nisso algum benefício pessoal imediato porque já estavam habituados a que fossem as populações do interior a aproximarem-se das suas terras para procederem às trocas comerciais, numa permanência secular de rotas que direccionavam para o litoral moçambicano e subiam depois para Norte, em direcção a Zanzibar. Lacerda cedo percebeu que seria difícil conseguir angariar carregadores profissionais que poderiam sair caro, para além de, como se ouvia dizer, estes carregadores poderem fazer apenas parte de um percurso, deixando depois a carga para outro carregador que cumpriria outro percurso, por motivos de delimitação de territórios linhageiros e de sociedades territorializadas. Restava-lhe socorrer-se de escravos que fariam esse trabalho, mesmo com o risco constante da sua fuga, com ou sem a carga que lhe dizia respeito.

$\mathrm{Na}$ realidade, o comércio de longa distância entre os territórios do Kazembe e de Tete já funcionava e Lacerda vai seguir o seu percurso. Estas rotas comerciais envolviam trabalhadores, negociantes, compradores e vendedores ao longo de todo o caminho. As rotas mercantis mantinham-se vivas graças à gente que dedicava toda a vida àquelas viagens de mercancia.

Nas caravanas, o principal meio de transporte eram os escravos e os carregadores. Paul E. Lovejoy descreve a estrutura e funcionamento das caravanas onde esses carregadores eram apenas mais um elemento na sua complexa hierarquia ${ }^{18}$. Havia carregadores profissionais mas também os escravos trazidos de casa, chamados de escravo de "corpo vendido" ${ }^{19}$, homens e mulheres que tinham a função de carregar as cargas à cabeça. Seria a tarefa mais difícil numa caravana porque eram alvo de assaltos e muitas vezes de exaustão, o que levava os escravos a abandonar as cargas e optar pela fuga. Os carregadores profissionais protegiam as suas cargas porque delas dependia o seu pagamento e asseguravam também a sua protecção junto do mercador. Mas os escravos carregadores limitavam-se ao alimento e à protecção do seu senhor.

A opção de Lacerda e Almeida pelos trabalhadores escravos dos proprietários de terras do território de Tete e de Sena pode ter sido intencional porque esse recurso não sairia tão caro e bastaria que fornecesse a cada um o alimento necessário. A própria relutância dos proprietários em ceder os seus carregadores seria também, para além de precisarem deles nos seus campos e casas, porque a função destes homens e mulheres não era de facto a de “carregador", aspecto que Lacerda e Almeida conheceria mas que não aplicou, porque lhe faltava o dinheiro para os contratar. Apenas a grande proprietária D. Francisca Josefa de Moura e Meneses não se opôs ao fornecimento de

\footnotetext{
${ }^{18}$ Lovejoy 2006 : 62.

${ }^{19}$ Capela $2002: 14$.
} 
escravos, ou melhor, de trezentas escravas que trabalhavam nas suas minas da Maxinga ${ }^{20}$.

Mas, para além da necessidade da força semovente dos escravos, uma lista endereçada por Lacerda à Fazenda Real permite conhecer alguns materiais e alimentos considerados para a viagem. Da lista de produtos, os únicos elementos relacionados com a alimentação são: louça (248 peças); café (2 arrobas); vinho (1 barrica). Por serem tão poucos elementos registados nesta lista podemos deduzir que o pedido à Fazenda Real visava angariar outros produtos e materiais que não se prendiam com a alimentação, uma vez que se pressupunha que os alimentos seriam reunidos em Sena.

O Feitor de Sena contribuiu para a expedição com alguns produtos, entre os quais: ${ }^{21}$

\begin{tabular}{|l|l|}
\hline Produtos & Quantidades \\
\hline Frascos de chá & 24 \\
\hline Copos de vinho e água & 12 \\
\hline Açúcar pedra & 1 arroba; 21 arráteis \\
\hline Pimenta redonda & 8 arráteis \\
\hline Almofariz de marfim e mão & 1 \\
\hline Açúcar pó & 12 arrobas \\
\hline Café & 4 arrobas \\
\hline Pedras de leite ${ }^{21}$ & 5.000 \\
\hline Frasqueiras de aguardente & 4 \\
\hline Açúcar pó & 5 arrobas; 16 arráteis \\
\hline Copos de vinho & 12 \\
\hline Copos de água & 21 \\
\hline Frasqueiras de manteiga & 4 \\
\hline Caçarolas grandes de cobre e tampas & 3 \\
\hline Caldeirinha grande de cobre & 1 \\
\hline Alqueires de trigo & 160 \\
\hline Frasqueiras de vinagre & 4 \\
\hline Alqueires de arroz & 180 \\
\hline Frasqueiras de azeite & 4 \\
\hline Cabeças de gado vacum & 30 \\
\hline Cabeças de gado miúdo & 94 \\
\hline Frasco de bebida & 1 \\
\hline Bules de chá & 2 \\
\hline Xícaras e pires & 10 \\
\hline Quissapos 22 de cebolas & 2 \\
\hline Quissapos de alho & 1 \\
\hline & \\
\hline
\end{tabular}

\footnotetext{
${ }^{20}$ Rodrigues 1999 : 90.

${ }^{21}$ Não conseguimos saber do que se trata exactamente.
} 
${ }^{22}$ Lacerda e Almeida teve também o cuidado de juntar produtos que facilitassem as trocas comerciais e diplomáticas com as populações que encontrassem pelo caminho, medicamentos e pessoal preparado ${ }^{23}$.

No entanto, em Sena, Lacerda reuniu poucos alimentos. A crise recente tinha dizimado vacas, ovelhas, porcos e carneiros. Muitos residentes faleceram e outros conseguiram sobreviver porque comiam raízes de bananeiras e de outros arbustos. Ainda assim, a expedição angariou arroz, milho-miúdo (para o pão), meixoeira (semelhante a alpista), naxinim (semelhante ao grão de mostarda, para fazer "azeite" para temperar os alimentos e para iluminação $0^{24}$, milho branco (só consumido verde), trigo, coco, gergelim, amendoim, abóboras, pepinos, melancias, batatas e inhames, laranjas, mangas, cajús, bananas, limas, goiabas. E ainda, do mar conseguiram reunir peixe, camarões, caranguejos, acrescentando-se, da caça, algumas aves e quadrúpedes.

Considerando que os alimentos reunidos eram perecíveis, e para que cada um carregasse e cuidasse do seu próprio alimento, foram distribuídas cargas de arroz pelos 60 carregadores que iniciaram a viagem, assim como algum sal. Aos oficiais entregou-se também chá, garrafas de águardente e "barrilotes" de vinagre. Aos soldados deu-se farinha de trigo, "frasqueiras de cachaça e aguardente do reino, que vinham para alguma precisão e presente para os Régulos”25, sal, vinagre e toucinho.

Em algumas aldeias por onde passaram, conseguiram reunir milho, batatas, inhames, amendoim e bananas e com mais sorte, galinhas, cabras e uma vaca ou boi que ajudavam a matar a fome por alguns dias. Noutras situações conseguiram melaço de cana-de-açúcar. Escreve o cientista: "deitam summo da cana em pequenos tachos, porque os não têm grandes, e o fazem ferver até tomar certo ponto, e depois o batem até tomar consistência de assucar" ${ }^{26}$. Para que os carregadores não fugissem e deixassem as cargas abandonadas, como se verificou em algumas situações, Lacerda decidiu que cada carregador ou carregadora tinha direito a algum "velório" (tecido) para que, nas aldeias por onde a expedição passasse, cada um pudesse ter oportunidade de negociar aquilo que precisasse, nomeadamente o "pombe", a bebida alcoólica preferida na região: "certa bebida fermentada, que fazem de milho" 27.

\footnotetext{
${ }^{22}$ Sacos.

${ }^{23} \mathrm{http} / /$ www.academia.edu/2609892/Os_Portugueses_e_a_travessia_do_continente_africano._Projectos_e_viagens_1755-1814;(18.03.2015; 22h).

${ }^{24}$ À semelhança da prática existente em algumas culturas europeias, também as populações do território de Manica recorriam a «um "azeite” "a cujas virtudes atribuem seus bons sucessos e fortuna para se prepararem para a caça ao elefante». Múrias $1936: 210$.

${ }^{25}$ Múrias 1936 : 188.

${ }^{26}$ Múrias 1936 : 168.

${ }^{27}$ Múrias 1936 : 177.
} 
A passagem pelas terras dos maraves obrigou ao entabulamento de relações diplomáticas. Sobre esta população, Lacerda diz que não executavam trabalhos de alguma "indústria", limitando-se a uma agricultura baseada na plantação de milho, batatas e inhames e uma espécie de feijão semelhante ao feijão guandú ${ }^{28}$ do Brasil. Este recurso à comparação dos alimentos do território africano com os do território brasileiro é frequente no diário de Lacerda porque a realidade sul-americana lhe era mais familiar e porque $o$ trabalho que ali realizara de delimitação das fronteiras e reconhecimento dos rios da colónia brasileira juntamente com o seu colega Silva Pontes, lhe dera muita informação ao nível da flora e da fauna, assim como dos usos e costumes das populações que habitavam as regiões por onde passaram. Foi junto dos maraves que Lacerda compreendeu a importância do sal no interior da África. O sal marinho era raro e as pessoas faziam uma espécie de sal a partir das cinzas de certas plantas, conforme o cientista descreve:

"Hoje vi um Marave estar fazendo sal. É uma lixívia extrahida da cinza; apenas tem o picante próprio da lixivia sem semelhança alguma ao picante e sabor do sal. Porém eles, acostumados a este sal, acharão talves nelle a mesma graça que nós achamos ao sal comum. Eu, entre os índios dos sertões do rio Negro, na $\mathrm{Ca}-$ pitania do Pará, vi um sal, que somente se diferia de sal marino na côr denegrida, porém não no gosto. Elle era tirado duma lixivia feita das cinzas de uns cocos pequenos e silvestres." ${ }^{29}$

Quanto mais a expedição avança para o interior do território africano mais difícil se torna adquirir alimentos. E quando surgia oportunidade de troca, tudo se tornava mais caro. Se nas terras dos muizas uma cabra custava um "chuabo" ${ }^{30}$, nas terras mais próximas do Cazembe não se conseguia uma cabra por menos de um seis ou mais "chuabos". Perante estas dificuldades, restava-lhe pescar os "pendes", pequenos e saborosos peixes de rio ${ }^{31}$ ou, o mais difícil, caçar "cavalos marinhos" 32 cuja carne, segundo Lacerda, era apreciada pelos muizas, já com algum grau de corrupção. O que leva o cientista a acrescentar: "Que poder não tem sobre nós a educação, os usos, os costumes e o exemplo!” 33 . É interessante semelhante observação de Lacerda e Almeida. $\mathrm{O}$ viajante não tem uma postura de crítica ou de menorização dos usos e

${ }^{28}$ Espécie de feijão originária da África Ocidental.

${ }^{29}$ Múrias 1936 : 197.

${ }^{30}$ Chuabo - população do território da Zambézia; neste caso pode tratar-se ou de um escravo originário daquelas terras ou mesmo de um tecido indiano. Inclinamo-nos mais para esta opção, já que Lacerda levou objetos para oferta.

${ }^{31}$ Múrias $1936:$ 210-216.

32 Hipopótamos.

${ }^{33}$ Múrias 1936 : 251. 
costumes das populações que encontra. Faz observações sem julgamentos de valor, numa perspectiva de admiração e de aceitação das práticas culturais e sociais, reconhecendo a diversidade cultural das sociedades, tal como já o fizera no Brasil. Na esteira dos cientistas do Iluminismo, Lacerda e Almeida reconhece qualidades entre os homens ou entre as culturas, especialmente a sua capacidade de sobrevivência em meios tão hostis.

Esta postura não se verifica nos registos de Capelo e Ivens. A viagem de Angola a contracosta foi previamente preparada em gabinete, com reservas de alimentos, vestuário, armas, tendas, medicamentos e outros objectos metidos em caixotes. Apesar de uma preparação cuidadosa, a doença, a fraqueza e outros desenganos reduziram a expedição a um número mínimo de homens e de bens. A estes juntava-se muitas vezes a minimização da esperança, especialmente quando a fome e a avitaminose sobrevinham: "A fome, eis o terror do sertão" ${ }^{34}$, logo reavivada quando os estômagos e os corpos se alimentavam, descansavam e retemperavam: "Tão pouco basta para contentar um espírito oprimido? Apenas acampados, celebrou-se gentilicamente a ventura do dia, abatendo um boi" ${ }^{35}$.

Capelo e Ivens só começam a manifestar séria preocupação com a alimentação e com a angariação diária de alimentos, a partir da passagem por Moçâmedes, relatada no capítulo $3^{\circ}$ do seu relato sobre a viagem de Angola a contracosta. Até lá, e enquanto perduram os alimentos trazidos em caixotes, esse problema não foi factor de registo e de preocupação, a não ser a descrição inicial dos preparativos da expedição onde se refere alguns produtos que eram transportados:

“... em lugar de uma centena de fardos de fazenda, dispusemos e organizámos vinte e sete de algodão e riscado; em vez de uma profusão de cargas de missanga, somente uma dúzia de sacos de cinquenta libras; para miudezas, instrumentos e raros presentes três caixas; quatro ditas para o que chamávamos rancho, isto é, chá, café, sal, açúcar e adubos ou temperos; e, finalmente, uma para artigos de mesa”"36.

Nos caixotes asseguraram-se tecidos e outros produtos que pudessem servir de saguate $^{37}$ (oferta), para além de panelas e louças para as refeições e outros requintes ocidentais, como o chá e o café. É mesmo de estranhar a aparente displicência, ou a ausência de relato exaustivo relativamente ao transporte de outros alimentos, enlatados, carne salgada ou seca, peixe seco, e

\footnotetext{
${ }^{34}$ Capelo e Ivens (s.d.) : I, 185.

${ }^{35}$ Capelo e Ivens (s.d.) : I, 212.

${ }^{36}$ Capelo e Ivens (s.d.) : I, 71.

${ }^{37}$ Presente, donativo, para fins diplomáticos ou para resolução de problemas de comunicação entre as partes.
} 
outros alimentos que seriam possíveis de conservar e transportar. Na realidade é estranho como é que dois viajantes que pretendiam que o seu diário servisse de directriz para futuros aventureiros, não se tenham atido numa listagem exaustiva de alimentos conservados que deveriam previamente ser embalados antes de se iniciar qualquer viagem. $\mathrm{O}$ certo é que mais adiante ficamos a saber que Capelo e Ivens levaram "umas tristes sardinhas de Nantes" ${ }_{38}$. Fica no ar a impressão de que a expedição terá sido preparada com algum facilitismo quando, já em terras do Quiteve, os viajantes confessam:

“...quando saímos dessa terra, mal pensaríamos que dali até ao grande Zambeze só em dois ou três lugares se encontraria mantimento em abundância, caso estranho, que raras vezes em África o viajante terá topado, e nos proporcionou angustiosos dias, apertados por este terrível mal" ${ }^{\prime 39}$.

À medida que a expedição de Capelo e Ivens penetrava na região central africana, as "fomes, sedes, desertos alternavam-se sistematicamente, para produzirem o seu máximo efeito no espírito da desnorteada caravana" ${ }^{40}$. A fragilidade do corpo e do espírito punha em causa a continuidade da aventura. Os homens estavam famintos, desanimados, ardentes de sede e, cansados, insistiam em continuar viagem e empurrar os 24 bois que eram a salvaguarda da sua sobrevivência. No entanto, o boi que se matava já não era o suficiente para saciar a fome. Os homens estavam extenuados e magros. Os próprios Capelo e Ivens perderam a elegância europeia da mesa e do trato com a comida, de tal modo que "exsudando sangue a carne assada nas brasas, que o cozinheiro nos enviava, sentíamos vontade de nos arrojarmos a ela, devorando-a por inteiro" ${ }^{41}$.

Os corpos esqueléticos reagiam a qualquer alimento que surgisse. Quando se cruzaram com carne de elefante dispersa no solo, resultante de uma antiga caçada, lançaram-se sofregamente aos pedaços já apodrecidos ${ }^{42}$. Só se abatia algum dos bois que seguiam com a expedição quando não se conseguia caçar ${ }^{43}$. É interessante verificarmos que o medo da fome e a alegria em redor do abate de um boi são sentimentos que se vão tornar predominantes à medida que o caminho percorrido é maior. E quando os corpos esgotavam, incapazes de mais um passo, havia que parar, semanas se necessário, para que se alimentassem e dormissem. Depois de refeitos voltavam ao caminho ${ }^{44}$. E durante esses

\footnotetext{
${ }^{38}$ Capelo e Ivens (s.d.) : I, 104.

${ }^{39}$ Capelo e Ivens (s.d.) : I, 185.

${ }^{40}$ Capelo e Ivens (s.d.) : I, 219.

${ }^{41}$ Capelo e Ivens (s.d.) : I, 224.

${ }^{42}$ Capelo e Ivens (s.d.) : I, 23.

${ }^{43}$ Capelo e Ivens (s.d.) : I, 25.

${ }^{44}$ Capelo e Ivens (s.d.) : I, 32.
} 
dias de descanso, Capelo e Ivens deliciavam-se com os seus antigos hábitos europeus, fumando cachimbo, bebendo chá e divagando.

Após longa caminhada de vinte e quatro horas, numa "deserta e longa floresta", o melhor momento acontecia quando o cozinheiro preparava a fogueira para nela assar carne na brasa, "ou nadando em um molho que pode ter por origem todos os ingredientes, desde o azeite de palma até ao tutano de elefante!". Cada vez com mais frequência, a refeição tornava-se a preocupação principal do dia perante o constante fantasma da "ameaça de fome" 45 , colocando os homens na mais ínfima das suas qualidades. Uma rude boçalidade que envergonhava os europeus habituados aos requintes e às boas maneiras à mesa:

“ À míngua de distracções de espírito, torna-se mais imperativo o gozo material de encher o estômago, aprecia mais essa ideia, domina-o grosseiramente o desejo sensual de ingerir o que vê, trazendo sempre interessado o receio das faltas frequentes. (...) e serenamente apreciámos em sua gastronómica grandeza os Hortênsios, Apícios e Lúculos, a quem a posteridade deve, pelo menos, considerar como homens de bom gosto." ${ }^{46}$

Esta derivação surgiu durante um fausto jantar de carne assada, em plena floresta dos territórios angolanos. E concluíram que, para o coroamento de uma refeição sublime, a presença dos convivas é imprescindível, conforme o «faraó Menes» já considerara ao classificar a mesa como uma razão de estado, ou o «legislador ateniense Sólon», que afirmara que um jantar refinado nunca deveria ter menos de 30 convivas $^{47}$. Em síntese, dois ocidentais, praticamente perdidos no meio de uma floresta, divagando, com saudade, sobre os requintes da mesa, a que decerto estariam habituados, como uma forma de resistência ao ambiente hostil onde se encontravam. ${ }^{48}$

E em cada longo dia que passava, descarregava-se o equipamento de cima dos animais e dos ombros e abatia-se mais um boi para matar a fome ${ }^{49} .$.

O dia de Natal de 1884 foi assinalado de forma singela, com um prato de feijão cozido, uma lata de peixe e uma lata de salsichas. À laia de champanhe, "uma pouca de farinha de sorgo de infusão em água" ${ }^{50}$.

Numa outra ocasião, o repasto à volta de uma presa de um enorme elefante colocou lado a lado homens e animais na sofreguidão esfaimada ${ }^{51}$. A carne de

\footnotetext{
${ }^{45}$ Capelo e Ivens (s.d.) : I, 160.

${ }^{46}$ Capelo e Ivens (s.d.) : I, 160.

${ }^{47}$ Capelo e Ivens (s.d.) : I, 160.

${ }^{48}$ Capelo e Ivens (s.d.) : I, 160.

${ }^{49}$ Capelo e Ivens (s.d.) : I, 212.

${ }^{50}$ Capelo e Ivens (s.d.) : II, 225.

${ }^{51}$ Capelo e Ivens (s.d.) : II, 113.
} 
elefante acabou por ser o recurso mais frequente quando se conseguia abater algum animal, obstando à já repetitiva carne de boi.

Nas conferências que proferiram mais tarde, Capelo e Ivens sublinharam a necessidade de se preparar muito bem a expedição, especialmente no que dizia respeito aos alimentos a transportar porque, asseguravam, seria muito mais fácil a um viajante sobreviver nas matas americanas do que nas africanas uma vez que, naquelas, havia recurso a vegetais e a gado enquanto nestas, a única coisa com que se poderia contar seria a caça, se tal fosse sucedida. Mesmo assim referem outros alimentos silvestres aos quais o viajante poderia recorrer: o chorchonus (raiz comestível), o ginguengue, "fruto avermelhado, de sabor extremamente ácido, alguns cogumelos agigantados, e nos meses de Setembro e Outubro a nocha, Parinarium mobola"52. Também poderiam socorrer-se da folha do baobá e da goma arábica da Akcacia albida. E ainda, do mel. Sobre as conservas europeias que se levariam em latas, "raras são as que sofram dois invernos sem se avariarem totalmente" ${ }^{53}$. Todas as conservas que levassem, avisavam os viajantes - sopas alemãs, chás, cafés -, deveriam ser colocadas ao sol, para não oxidarem. Os açúcares, frutas e doces deveriam ser suprimidos e o melhor seria optar pelo café, chá e "muito sal, condimentos em frascos fortes, e quantos aperitivos se proporcionarem" ${ }^{54}$. Todas as especiarias que se pudessem levar seriam aconselháveis porque eram úteis para o cozimento de carnes. E, eventualmente, o arroz se se conseguisse transportar em condições.

Mas, pior do que a fome, dizem Capelo e Ivens, era a sede. E quando os líquidos faltavam e não tinham acesso à água potável, aconselhavam a que molhassem os corpos para que a frescura da água lhes amenizasse a sede ${ }^{55}$. Para além da fome e da sede, outros pormenores referentes às dificuldades que enfrentaram são a "morte de alguns elementos da caravana" e os "costumes dos indígenas" ${ }^{56}$.

Apesar de irem conseguindo matar a fome, e de vez em quando acederem a maior diversidade de alimentos, os viajantes não se livraram do aparecimento de úlceras nas gengivas, que classificaram de "escorbuto do sertão" ${ }^{57}$.

${ }^{52}$ Capelo e Ivens (s.d.) : II, 55.

${ }^{53}$ Capelo e Ivens (s.d.) : II, 55.

${ }^{54}$ Capelo e Ivens (s.d.) : II, 55.

${ }^{55}$ Capelo e Ivens (s.d.) : II, 118.

${ }^{56}$ Teresa Bernardino, As viagens de Capelo e Yvens. Portugal em África na segunda metade do século XIX. http://comum.rcaap.pt/bitstream/123456789/3428/1/NeD36_TeresaBernardino. pdf. (01.09.2014).

${ }^{57}$ Capelo e Ivens (s.d.) : II, 161. 


\section{Contextos alimentares}

A descrição de contextos alimentares onde se processa o encontro entre os viajantes e os chefes das aldeias, ou mesmo no cenário de uma refeição pelo grupo de expedicionários, não surge com frequência em Lacerda e Almeida, contrariamente ao que veremos depois nas memórias de Capelo e Ivens.

Se considerarmos que o texto de Capelo e Ivens é feito a posteriori, jogando com as memórias e com o que era importante deixar para os futuros viajantes em terras africanas, houve com certeza tempo para compilar essas mesmas memórias e alargar as descrições. Lacerda escreveu ao momento, e à medida que a doença ia permitindo. Talvez por isso faltem descrições mais alargadas das experiências no terreno.

Lembremos que Lacerda fez toda a viagem sempre doente, o que pode justificar que se tenha registado apenas uma situação de contexto alimentar num encontro com "o outro". Dificilmente teria tido oportunidade de se deslocar junto dos chefes das aldeias, limitando-se a trocas de ofertas à distância. Foi o que aconteceu quando chegou às terras do chefe Caperemera. Lacerda ofereceu-lhe um xaile, uma "peça de zuzarte" ${ }_{58}$ "um frasco de cachaça" e um de "pano de cauril" 59 . Em troca, Caperemera enviou-lhe um bolo ${ }^{60}$. Numa ocasião em que as febres já atacavam fortemente o cientista, Lacerda negociou com os muizas direitos de passagem e conseguiu reunir algum milho, batatas, inhames, amendoins e bananas. Só uns dias mais tarde conseguiu obter cabras e gado vacum para permitir que a expedição continuasse viagem.

Nas muitas observações que registam sobre a geografia do espaço que vão desbravando, Capelo e Ivens descrevem, pontualmente, a alimentação praticada por algumas das populações com quem vão contactando e com quem, em algumas situações, partilharam refeições.

Quando chegaram às terras de Moçâmedes, a monocultura do milho, a par do algodoeiro, revelava que aquele alimento seria predominante no quotidiano das populações, para além de, a par do algodão, ser integrado na rede do comércio para fora da região.

Já no território do Quiteve, o leite era o alimento predominante, do qual se alimentavam à noite, acompanhado de pequena porção de milho. Dizem Capelo e Ivens que, durante o dia, as pessoas bebiam apenas uma bebida alcoólica feita a partir do milho - a garapa. Ainda segundo os autores, estas populações passariam fome uma vez que, quando havia carne para refeição “...ou outro qualquer artigo em abundância devoram-no sofregamente!” 61.

\footnotetext{
${ }^{58}$ Zuzarte ou zuarte é um tecido de algodão azul.

${ }^{59}$ Cauril - concha de molusco ou búzios que servia de moeda no sertão oriental.

${ }^{60}$ Múrias 1936 : 205, 210.

${ }^{61}$ Capelo e Ivens (s.d.) : I, 153.
} 
Sobre os usos e costumes relacionados com a subsistência das populações é-nos dada ainda a descrição sobre as festas das colheitas das populações bancúmbis, que se realizavam em Fevereiro. Nelas predominava uma bebida "extremamente inebriante" 62 feita a partir de um fruto de nome gongó. Outra festa realizava-se em Setembro, na qual a "mulher" do chefe da aldeia distribuía sementes pela população e também ela ia semear num terreno do chefe, acompanhada pelo feiticeiro, dando depois início a danças que duram dias ${ }^{63}$. $\mathrm{O}$ desejo de um ano produtivo e todo o cerimonial inerente revelavam que a sobrevivência das populações era muito frágil, dependendo totalmente da natureza e da sua benignidade ${ }^{64}$.

Nas terras dos amboelas viram mandioca, depois de tantos longos dias sem descobrirem essa raiz nas hortas de outras populações, para além do milho e da batata. A estes alimentos juntava-se o peixe pescado no rio.

Nas terras dos dimbas, o mês do término das colheitas era Junho, culminando os trabalhos com a festa da hela, da paz e da abundância, na qual se bebia muito e se obrigava os chefes das aldeias a partilharem os alimentos sob risco de perderem a vida durante a cerimónia, em caso de recusa. Para além de dar nome à festa, a hela era uma cerveja feita a partir do sorgo "que, depois de humedecido, seco e triturado, é metido num funil de capim para dirigir a água coada através da massa, que mais tarde, fermentando, constitui a bebida" ${ }^{65}$.

Em Garanganja encontram-se com o chefe da região. Depois das trocas de mensagens diplomáticas e da oferta, por parte do chefe africano, de pombé, farinha, arroz, feijão, milho, frutas e chibatos. Só três dias depois deste cerimonial de boas vindas é que o "poderoso régulo da África Central" aceitou ver o rosto dos seus visitantes.

Num outro acampamento, em Tacata, para além de se alimentarem melhor, especialmente com recurso a vegetais, permitiam que as gentes se juntassem para trocar produtos: farinhas, aves, legumes, peixes. O grupo sentia, nesta dinâmica de gentes e de produtos, algum conforto que os animava para continuar viagem.

As terras da Zambézia começaram a revelar mais alimentos. Felizmente, o encontro com os povos mandumbas permitiram-lhes variar a ementa, desta feita com ratos, espigas de milho e raízes de mandioca ${ }^{66}$. Uma outra comitiva de mandumbas deu as boas vindas à expedição, com carne de elefante seca. $\mathrm{O}$ que não significava fartura desta carne porque, caçar um elefante era arriscado

\footnotetext{
${ }^{62}$ Capelo e Ivens (s.d.) : I, 171.

${ }^{63}$ Capelo e Ivens (s.d.) : I, 172.

${ }^{64}$ Capelo e Ivens (s.d.) : I, 173.

${ }^{65}$ Capelo e Ivens (s.d.) : I, 157.

${ }^{66}$ Capelo e Ivens (s.d.) : I, 225.
} 
e muito difícil. A base da alimentação era o mel com a carne a acompanhar ${ }^{67}$. Juntava-se a este cabaz a farinha (provavelmente de mandioca), que os autores consideraram que, embora não tivesse grande valor nutricional, pelo menos, tinha o condão de fazer variar a ementa ${ }^{68}$.

No território de Zambeze a expedição de Capelo e Ivens encontra-se com Muene N'Tenque de Uniamuezi. O relato deste encontro revela como funcionou a estrutura diplomática do chefe africano e como o tempo e a relação cuidada com os estranhos foi devidamente trabalhada. As diferenças culturais sobressaíram e Capelo e Ivens registaram-nas, caricaturando as pessoas com quem contactaram. Segundo a descrição dos viajantes, só dois dias depois de chegarem às terras de N'Tenque é que foram recebidos, na cerimónia de "visita de cumprimento". Os portugueses, em contrapartida, convidaram o N'Tenque para que visitasse o seu acampamento, o que aconteceu pela hora de jantar. $\mathrm{O}$ primeiro a sentar-se foi o chefe africano, sentando-se imediatamente a seu lado, no chão, "um célebre irmão mais velho, que, trajando "à paraíso", coberta a cabeça por enorme chapéu alto, se conservou todo o tempo de cócoras e embasbacado para a estranha cena de uma refeição à europeia!" ${ }^{69}$ Quando o repasto iniciou, as diferenças comportamentais à mesa acentuaram-se. Foram servidos pratos com sopa e colher, o que indica que ainda permaneciam alguns instrumentos na carga dos expedicionários. N'Tenque começou a dar colheradas de sopa a todos os presentes, a partir do seu prato, forçando os seus acompanhantes vassalos e os europeus a digerirem a mesma sopa pela mesma colher. Sem capacidade de resposta por parte destes: "Então toma de novo a [sopa] de Capelo e prova do prato deste; inopinadamente dois filhos querem também provar; à confusão das colheres sucede-se a das frases, o ruído aumenta; é mais a saliva que o caldo nos pratos...”70.

Sobre o horário aconselhável para se fazer as refeições, Capelo e Ivens aconselham que o pequeno-almoço fosse tomado muito cedo e que o almoço decorresse à hora de calor, numa zona de sombra onde depois pudessem descansar. O jantar era escusado para que se deitassem cedo, descansassem e poupassem comida e esforços. Os frutos silvestres eram desaconselhados, porque poderiam afectar o trato intestinal.

Em Caponda, as hortas mostravam abóboras, milho e pepino. Em consequência, as ementas foram melhoradas nos dias em que passaram por aquelas terras, preparando-se depois para mais uma fase da viagem em que voltaram à frugalidade de uma carne seca sobre as brasas ${ }^{71}$.

\footnotetext{
${ }^{67}$ Capelo e Ivens (s.d.) : I, 263.

${ }^{68}$ Capelo e Ivens (s.d.) : I, 284.

${ }^{69}$ Capelo e Ivens (s.d.) : I, 45.

${ }^{70}$ Capelo e Ivens (s.d.) : I, 45.

${ }^{71}$ Capelo e Ivens (s.d.) : I, 122.
} 
Chegados a terras do chefe Moi-Quinhama foram recebidos com a oferta de milho, galinhas, carne de hipopótamo e panelas de pombé. Pouco depois foram ainda contemplados com outra dose de alimentos: pombos, carne de antílope e peixes do rio Luapula ${ }^{72}$. Nesta região permaneceram por alguns dias para pescarem e secarem peixe que levaram para a viagem ${ }^{73}$.

\section{EM CONCLUSÃO}

Os textos de Lacerda e Almeida e de Capelo e Ivens ajudam-nos a interpretar como foi o olhar dos homens de setecentos e de oitocentos relativamente às populações africanas. O diário de Lacerda revela alguém que, formado segundo os padrões culturais europeus, se deixou fascinar pela excentricidade e pelo exotismo dos usos e costumes das populações africanas. Daí surgirem observações reveladoras de admiração pela organização social ou pelos procedimentos culturais das populações com quem se cruzou na sua viagem desde Tete às terras do Cazembe. Ou ainda, comparações com outros lugares por onde passou, outras gentes, outros usos e costumes, especialmente no Brasil.

Apesar das duas viagens terem como objectivo principal a travessia da África e o conhecimento da sua geografia, dos recursos naturais e de aspectos dos usos e costumes das populações, através das descrições dos seus autores conseguimos extrair informação que nos ajuda a vislumbrar quais os alimentos que constariam das expedições científicas e exploratórias do território africano, e de que modo os europeus olharam para o "outro" identitário num contexto em que se processa, por exemplo, uma refeição. Ou seja, para além de se pretender conhecer "o outro", com objectivos comerciais, exploratórios, políticos, militares e de evangelização, esse "outro" configurava-se, ao olhar europeu, como um "bárbaro" com usos e costumes "pagãos", em contraposição à civilização europeia. De facto, numa primeira fase da presença dos portugueses em África, vamos encontrar textos que reflectem a imagem superficial que se tinha do africano, tal como Gomes Eanes de Zurara afirmara, no século $\mathrm{XV}$, que os "guinéus" eram gente de "fealdade extrema..." ${ }^{74}$.

Dos materiais e produtos reunidos por Lacerda e Almeida para a viagem consideramos apenas os alhos, cebolas, gado vacum e miúdo, azeite, manteiga, arroz, chá, vinagre, trigo, açúcar, pedras de leite, pimenta e vinho como os alimentos fundamentais para a sobrevivência dos participantes. De total inutilidade seriam as 248 peças de louça, os 12 copos de vinho e 21 de água, as 4 frasqueiras de aguardente, as 10 xícaras e pires, que só se entendem integrados no próprio quadro civilizacional do cientista e dos seus

\footnotetext{
${ }^{72}$ Capelo e Ivens (s.d.) : I, 146,147.

${ }^{73}$ Capelo e Ivens (s.d.) : II, 159.

${ }^{74}$ Zurara 1981 : 342-537.
} 
companheiros europeus, para quem toda aquela louça seria algo inevitável para o seu quotidiano, mesmo no inóspito interior africano. Os modelos sociais do "estar à mesa" para homens formados em ambientes de requinte eram replicados nas terras de África. $\mathrm{Na}$ fase preparatória da viagem não se pensava em recorrer aos produtos e materiais da região, mais adequados às necessidades e às circunstâncias limitativas da deslocação e da escassez de carregadores.

Por oposição a Lacerda e Almeida, os dois viajantes, Capelo e Ivens, revelam maior cuidado na preparação da viagem mas acentuam a sua exigência nos materiais que pretendem levar para a viagem. Quando Capelo e Ivens chegam ao fim da viagem, a comida já abundava e os corpos estavam satisfeitos. Fala-se então, do espírito da missão cumprida e do encerramento de um tempo de fome, de incógnitas e de medos. Terminada a travessia e cumprido o objectivo de ligar por terra os dois oceanos Atlântico e Índico, já seria possível dar continuidade à política de "conquista civilizadora" da África ${ }^{75}$ por parte de Portugal. Demonstrava-se também aos outros países europeus que Portugal controlava um território vasto entre as suas duas maiores colónias, permitindo apresentar o projecto do Mapa Cor-de-Rosa que desenhava um território único entre Angola e Moçambique. Projecto que acabou por ficar suspenso com a resposta do Ultimato britânico em 1890 .

Não obstante toda a concepção política e estratégica baseada na intencionalidade das viagens de Lacerda e de Capelo e Ivens, procurou-se perceber como essas aventuras se processaram no terreno e em cada dia de esperança ou desalento. Foi feita uma análise aos excertos dos textos, que revelaram a forma como as expedições sobreviveram à fome e à sede, num contexto geográfico globalmente inóspito.

Os viajantes apresentaram algumas conclusões que retiraram da sua experiência e uma delas é o facto de ser conveniente que qualquer expedição vá bem apetrechada de alimentos porque contrariamente ao que se poderia pensar, foi difícil caçar nos territórios por onde passaram e os alimentos mais fáceis de recolecção escasseavam ou não eram bons para a saúde humana. A própria água, quando surgia, poderia não ser potável.

O maior conselho que Capelo e Ivens deram aos seus ouvintes nas conferências que realizaram depois da viagem foi a de nunca esquecerem de tomar o quinino para prevenção da malária, causa principal de morte naquelas terras.

Sobre as populações com quem contactaram, apesar de os viajantes terem passado por períodos em que dependiam totalmente dos outros para conseguirem sobreviver, verifica-se que Capelo e Ivens não abandonam uma

\footnotetext{
${ }^{75}$ Santos $1988: 313$
} 
postura de superioridade civilizacional, não obstante cumprirem respeitosamente todos os tempos, manobras, gestos e decisões diplomáticas de acordo com os anfitrióes que foram conhecendo ao longo da viagem.

As informações que forneceram no texto sobre usos e costumes alimentares e agrícolas dos povos africanos no território percorrido não são extensas e pouco informam. No entanto, pode-se desenhar, embora palidamente, a produção maioritária de milho, feijão e farinha (provavelmente de mandioca e de outros cereais), mandioca, sorgo e arroz. Acrescentam-se alguns produtos hortícolas como abóbora, pepino e batata. Recorriam também a alguns frutos, que os autores dos textos não nomearam. Nos lugares onde existiam rios, as pessoas recorriam ao peixe, que comiam fresco ou seco. $\mathrm{O}$ recurso à carne de caça e de aves era outra forma de assegurar a alimentação das populações das aldeias que também teriam rebanhos de cabras, conforme a oferta de um "chibato" pode comprovar. O leite era muito usado por determinados povos. No entanto não há uma menção clara à origem do leite que os viajantes disseram ter bebido. Havendo aves de criação, com certeza que os ovos seriam outro recurso alimentar.

Apesar de reduzidas, as informações sobre a tipologia alimentar das populações africanas é mais rica em De Angola à Contracosta do que no Diário de Lacerda e Almeida. No entanto, outros textos poderão juntar-se a este estudo. Uma abordagem antropológica mais próxima poderá inclusive ajudar a compreender mais alargadamente a dieta alimentar das populações africanas numa perspectiva histórica.

Os caminhos difíceis do interior africano forçaram os europeus a mudar de opinião face à necessidade da colaboração das sociedades com quem os viajantes se cruzavam para garantia da sua própria sobrevivência. Quando a ausência de alimento coloca em risco a vida dos viajantes europeus e seus escravos e carregadores, a atitude tende a adquirir uma face mais humilde. Afinal, estava-se num contexto em que o alimento determinava o jogo da vida ou a morte.

\section{Bibliografia Final}

\section{Artigo em Periódico}

Alberto, M. S. (1950), "Dr. Lacerda e Almeida. Contribuição para a sua biografia e para a História da sua viagem ao Cazembe", Documentário Trimestral 63: 89-123.

Pereira, M. R. de M.; Cruz, A. L. R. (1999), "Brasileiros a serviço do Império: a África vista por naturais do Brasil, no século XVIII”, Revista Portuguesa de História 33: 153-190.

Rodrigues, E. (2011), "Ciência europeia e exploradores africanos: a viagem de Francisco José de Lacerda e Almeida ao Kazembe”, Africana Studia 16: 81-102. 


\section{Contribuição em Livro:}

Fage, J. (1982), “A evolução da historiografia africana”, in J. Ki-Zerbo (org.), História Geral da Africa: Metodologia e Pré-História da África, Ática, São Paulo, I-43-59.

\section{Livro}

Albuquerque, L. (1973), Para a História da Ciência em Portugal, Livros Horizonte, Lisboa. Andrade, A. A. B. (1955), Relações de Moçambique Setecentista, Agência Geral do Ultramar, Lisboa.

Baumer, F. L. (1990), O Pensamento Moderno Europeu, Edições 70, Lisboa.

Capela, J. (1993), O Escravismo Colonial em Moçambique, Edições Afrontamento, Porto.

Capela, J. (2002), O Tráfico de Escravos nos Portos de Moçambique, Edições Afrontamento, Porto.

Capelo, H.; Ivens, R. (s.d.), De Angola à Contracosta, Publ. Europa-América, Lisboa.

Domingues, A. (1991), Viagens de exploração geográfica na Amazónia em finais do século XVIII: politica, ciência e aventura, Centro de Estudos de História do Atlântico, Funchal.

Eça, F. G. A. (1951), Lacerda e Almeida. Escravo do dever e mártir da ciência (1753-1798), Tipografia Severo Freitas, Lisboa.

Flandrin, J.-L.; Montanari, M. (1996), Histoire de l'Alimentation, Fayard, Paris.

Flandrin, J.-L.; Montanari, M. (2008), História da Alimentação, Terramar, Lisboa.

Fonseca, Q. (1936), Um Drama no Sertão. Tentativa da travessia de África em 1798, Tipografia Minerva, Famalicão.

Lovejoy, P. E. (2000), Transformations in Slavery, A History of Slavery, Cambridge University Press, Cambridge.

Múrias, M. (1936), Travessia da África pelo Dr. Lacerda e Almeida, Divisão de Publicações e Biblioteca da Agência Geral das Colónias, Lisboa.

Santos, M. E. M. (1988), Viagens de exploração terrestre dos portugueses em África, Centro de Estudos de História e Cartografia Antiga, Lisboa.

Silva, A. C. (2012), Imagens da África: da Antiguidade ao Século XIX, Penguin, São Paulo. Zurara, Gomes Eanes de (1981), Crónica dos feitos notáveis que se passaram na conquista de Guiné por mandado do Infante D. Henrique, Academia Portuguesa de História, Lisboa.

\section{Sítios electrónicos}

Martins, Luísa Fernanda Guerreiro, 1997, Francisco José de Lacerda e Almeida, Travessias Cientificas e Povos da África Central (1797-1884), dissertação de mestrado em História dos Descobrimentos e da Expansão Portuguesa apresentada à Faculdade de Letras da Universidade de Lisboa, exemplar policopiado.

http://dited.bn.pt/30909/1897/2357.pdf; (01.09.2014). 
Bernardino, Teresa, As viagens de Capelo e Yvens. Portugal em Árica na segunda metade do século XIX.

http://comum.rcaap.pt/bitstream/123456789/3428/1/NeD36_TeresaBernardino.pdf; (01.09.2014).

https://books.google.pt/books?id=iAM5AQAAIAAJ\&pg=PA168\&lpg=PA168\&dq= o+que+\%C3\%A9+um+chuabo\&source=bl\&ots=uVTPKHcH_k\&sig=Kn9ym sObwbyicc9z4CcYNp4Qz7c\&hl=pt-PT\&sa=X\&ei=vhIUVY_nOoGqUcjTg KAN\&ved=0CEoQ6AEwCDgK\#v=snippet\&q=lacerda\&f=false; (27.03.2015; 14h).

http://www.academia.edu/2609892/Os_Portugueses_e_a_travessia_do_continente_ africano._Projectos_e_viagens_1755-1814;(18.03.2015; 22h).

http://arlindo-correia.com/120109.html;(30.03.2015, 23h).

https://www.academia.edu/1862040/Redes_mercantis_e_expans\%C3\%A3o_ territorial._A_penetra\%C3\%A7\%C3\%A3o_portuguesa_no_vale_do_ Zambeze_e_na_\%C3\%81frica_central_durante_o_s\%C3\%A9culo_ XIX_1798_1890_._Stvdia_54_55_1996_165-210._IS S N_08700028;(30.03.2015; 23h15m).

http://www.academia.edu/2609892/Os_Portugueses_e_a_travessia_do_continente_ africano._Projectos_e_viagens_1755-1814_;(30.03.2015; 23h30m).

http://www.humanas.ufpr.br/portal/cedope/files/2011/12/In\%C3\%A1cioCaetano-Xavier-e-Francisco-Jos\%C3\%A9-de-Lacerda-e-AlmeidaMo\%C3\%A7ambique-em-dois-relatos-ou-sonhos-Jos\%C3\%A9-RobertoBraga-Portella1.pdf; (30.03.2015; 23h35m).

Lovejoy, Paul E., "Mercadores e carregadores das caravanas do Sudão Central, século XIX", Tempo - Revista Digital do Departamento e do Programa de Pós-Graduação em História da Universidade Federal Fluminense, no 20, p. 61.

http://www.historia.uff.br/tempo/site/?cat=48; (25.09.2015; 22h). 